\title{
Shallow Cumulus in WRF Parameterizations Evaluated against LASSO Large-Eddy Simulations
}

\author{
WAyne M. Angevine, Joseph Olson, And Jaymes KenYon \\ Cooperative Institute for Research in Environmental Sciences, University of Colorado Boulder, \\ and NOAA/Earth System Research Laboratory, Boulder, Colorado \\ WILLIAM I. GUSTAFSON JR. \\ Atmospheric Sciences and Global Change Division, Pacific Northwest National Laboratory, Richland, Washington \\ SATOSHI ENDO \\ Environmental and Climate Sciences Department, Brookhaven National Laboratory, Upton, New York \\ KAY SUSELJ \\ Jet Propulsion Laboratory, California Institute of Technology, Pasadena, California \\ DAVID D. TURNER \\ NOAA/Earth System Research Laboratory, Boulder, Colorado
}

(Manuscript received 2 April 2018, in final form 12 October 2018)

\begin{abstract}
Representation of shallow cumulus is a challenge for mesoscale numerical weather prediction models. These cloud fields have important effects on temperature, solar irradiance, convective initiation, and pollutant transport, among other processes. Recent improvements to physics schemes available in the Weather Research and Forecasting (WRF) Model aim to improve representation of shallow cumulus, in particular over land. The DOE LES ARM Symbiotic Simulation and Observation Workflow (LASSO) project provides several cases that we use here to test the new physics improvements. The LASSO cases use multiple largescale forcings to drive large-eddy simulations (LES), and the LES output is easily compared to output from WRF single-column simulations driven with the same initial conditions and forcings. The new MellorYamada-Nakanishi-Niino (MYNN) eddy diffusivity mass-flux (EDMF) boundary layer and shallow cloud scheme produces clouds with timing, liquid water path (LWP), and cloud fraction that agree well with LES over a wide range of those variables. Here we examine those variables and test the scheme's sensitivity to perturbations of a few key parameters. We also discuss the challenges and uncertainties of single-column tests. The older, simpler total energy mass-flux (TEMF) scheme is included for comparison, and its tuning is improved. This is the first published use of the LASSO cases for parameterization development, and the first published study to use such a large number of cases with varying cloud amount. This is also the first study to use a more precise combined infrared and microwave retrieval of LWP to evaluate modeled clouds.
\end{abstract}

\section{Introduction}

Shallow cumulus fields have important effects on the surface and atmosphere (Ma et al. 2018; Van Weverberg et al. 2018), but are challenging to model (Arakawa 2004; Neggers et al. 2004) and difficult to observe

Corresponding author: Wayne M. Angevine, wayne.m.angevine@ noaa.gov quantitatively. Recently, some attention has been focused on these cloud fields over land, to complement more extensive studies over water. Here, we report on tests of new physics in the WRF Model for shallow cumulus cases. The single-column model (SCM) runs are driven by forcing data prepared for the DOE LES ARM Symbiotic Simulation and Observation (LASSO) project, and compared with large-eddy simulations (LES) produced by LASSO that are driven by those same 
forcing data. From the wide variety of large-scale forcing combinations and LES runs available, we chose a small subset that nonetheless covers a broad range of cloud properties within the shallow cumulus range. We find good correspondence between the SCM and LES, particularly for cloud cover, liquid water path, and their diurnal cycles, and we analyze and discuss points of agreement and disagreement. Sensitivity of the scheme to perturbations of two key parameters is tested.

This paper demonstrates the first application of ARM's new LASSO data bundles for improving parameterization of the boundary layer and shallow clouds. Our work shows the value of moving beyond single case studies and the typical idealized LES test cases and using multiple simulated days under the same meteorological regime of shallow convection. This helps identify how well EDMF captures this regime, which, as is shown in the five cases used in this study, can vary in the subtleties that lead to the cloud formation. Within those 5 case days, we use different initialization and forcing data to expand the number of simulations to 15 . The differences would not be easily identified using one or a few idealized cases.

\section{The MYNN-EDMF and TEMF schemes in WRF}

The new Mellor-Yamada-Nakanishi-Niino (MYNN) eddy diffusivity mass-flux (EDMF) boundary layer and shallow cloud scheme and the older, simpler total energy mass-flux (TEMF) scheme belong to the family of eddy diffusivity mass-flux schemes for vertical turbulent mixing in mesoscale models. While these are commonly called "PBL schemes," it is worth noting that in WRF they are responsible for all vertical turbulent mixing, not only that occurring in the planetary boundary layer. EDMF schemes provide a natural, physically appealing way to handle the problem of nonlocal transport in the convective boundary layer, and a natural expression of the connection between dry thermals and cumulus clouds. Because shallow cumulus schemes are part of the boundary layer, the preferred solution is an integrated boundary layer and shallow cumulus scheme rather than separate schemes (Arakawa 2004). Using EDMF, there is no need for a triggering condition for cumulus clouds to form, or for a closure formulation at cloud base.

Chatfield and Brost (1987) may have been the first to combine eddy diffusivity, commonly used for PBL mixing, with mass flux, commonly used to represent the vertical transport within cumulus clouds. Since about the year 2000, many EDMF schemes have been developed (Angevine 2005; Hourdin et al. 2002; Pergaud et al. 2009; Rio and Hourdin 2008; Siebesma and Teixeira 2000; Siebesma et al. 2007; Neggers et al. 2009;
Sušelj et al. 2012, 2013, 2014) and several have been implemented in operational models including the ECMWF Integrated Forecast System (Köhler et al. 2011), the U.S. Navy Global Environmental Model (Sušelj et al. 2014), and the NCEP GFS (Han et al. 2016).

The TEMF scheme (Angevine 2005; Angevine et al. 2010) has been available in WRF for several versions. Here we use it as an example of a relatively simple scheme, having a single updraft. TEMF has been successfully deployed in several research studies (Angevine et al. 2012, 2013, 2014; Huang et al. 2013; Mielikainen et al. 2015). Some parameters are modified to improve (tune) its performance for one of the LASSO cases, as described in the discussion section below. In TEMF, the updraft mass flux and vertical velocity are specified at the lowest model level; therefore, the updraft area is diagnosed and varies with height. The initial updraft area is approximately $6 \%$.

MYNN-EDMF is an enhancement of the MellorYamada-Nakanishii-Niino PBL parameterization (Nakanishi and Niino 2009) that has been available in WRF for many versions. Its development is primarily targeted toward the operational Rapid Refresh (RAP) and High Resolution Rapid Refresh (HRRR) models (Benjamin et al. 2016), but the MYNN scheme is also widely used in other WRF applications. The EDMF version has been available since version 3.8 (2016) but was turned off by default; it is turned on by default in WRF, version 4.0, released in June 2018. MYNN-EDMF is the first multiplume EDMF scheme for an operational model in the United States. A full description of the scheme and its evolution will be provided by Olson et al. (2018, unpublished manuscript). For the present purposes, we note a few vital points about the mass-flux part of the scheme. It uses up to 10 updrafts, each representing plumes of discrete diameters $(100-1000 \mathrm{~m}$ in increments of $100 \mathrm{~m}$ ), the number of plumes being variable depending on the boundary layer height (PBLH) and horizontal grid spacing $(\Delta x)$. All plumes with diameter smaller than the PBLH and less than $\Delta x$ are available for activation. Making the maximum vertically coherent plume width approximately equal to the PBLH follows results from LES cases (Neggers et al. 2003) and satellite observations (Cahalan and Joseph 1989). For the SCM tests reported here, the grid spacing, which has no other effect on the solution, is set to $13 \mathrm{~km}$, so all 10 updrafts are available.

The initial updraft velocity and scalar properties are specified for each updraft at the surface. Each plume is integrated upward until the vertical velocity becomes negative. The fractional entrainment rate for each plume is $l=0.5 /\left(w_{i} d_{\mathrm{i}}\right)$, where $w_{i}$ and $d_{i}$ are the vertical velocity and diameter of plume $i$, respectively. This 
diameter-dependent entrainment rate allows each plume to evolve differently, thus attempting to represent a broad range of thermals in a convective boundary layer. It is similar to the method of Tian and Kuang (2016). With the diameter of each plume assumed to be held constant with height, only the variation of the vertical velocity with height (see the appendix) can vary the mass flux with height. There is no explicit detrainment in the MYNN-EDMF scheme.

The total updraft area of all plumes in a grid column $a_{u}$ is a function of the surface buoyancy flux $Q$ (in kinematic units). The purpose is to act as a "soft triggering" mechanism, as discussed in Neggers et al. (2009), allowing the mass flux to ramp up during the morning hours and taper off more slowly in the evening transition. We use a hyperbolic tangent function to control this variation:

$$
a_{u}=0.5 \times \tanh [(Q-0.03) / 0.09]+0.5,
$$

so $a_{u}$ is about $\sim 10 \%$ for $Q>0.3 \mathrm{~K} \mathrm{~m} \mathrm{~s}^{-1}$ but can be as small as $\sim 2 \%$ for $Q$ near 0 . Thus, the total area fraction of all coherent plumes is not directly related to the conceptual size of individual plumes. The contributions of all activated plumes are then averaged according to a power law, expressing the number density of plumes as a function of plume width, to represent the mean ensemble of plumes covering $a_{u}$ in a model column. This multiplume-size concept was inspired by the work of Neggers (2015).

Other key design aspects of the mass-flux scheme within MYNN-EDMF include the following:

1) The form of the vertical velocity equation is taken from Simpson and Wiggert (1969) (see the appendix), similar to other mass-flux schemes.

2) The activation of the mass-flux scheme requires a positive surface buoyancy flux and a superadiabatic profile in the lowest $50 \mathrm{~m}$ of the model atmosphere.

3) The eddy-diffusion and mass-flux components are solved simultaneously using a semi-implicit method following Siebesma et al. (2007).

Cloud in the WRF SCM running MYNN-EDMF can be produced by three processes:

1) The mass-flux component produces clouds when one or more updrafts reach above their lifting condensation level and condense. In both TEMF and MYNN-EDMF, the updraft condensation occurs at saturation and is restricted to liquid only. In this case, the cumulus cloud fraction is calculated according to Chaboureau and Bechtold (2005) and is not identical to the updraft area fraction.
2) A nonconvective subgrid component derived from Chaboureau and Bechtold (2002) produces cloud when relative humidity and the variance of the saturation deficit are sufficiently large that some portion of the grid cell is estimated to condense.

3) The microphysics scheme produces grid-scale cloud when the grid-scale relative humidity reaches $100 \%$.

Clouds produced by these three processes are referred to below as mass flux (MF), nonconvective subgrid (NCS), and grid-scale cloud.

All parameterization schemes for operational or quasioperational models must run reliably in all conditions without crashing or producing obviously wrong results for numerical reasons. Therefore, all schemes include some limits or safety barriers in addition to their conceptually driven formulation. The code used here is the same as that implemented into in WRF-ARW, version 4.0, and can be studied in the appendix or in the WRF release.

\section{LASSO}

The LASSO project was designed to bring together observations and LES to improve physical parameterizations in numerical models, among other goals (Gustafson et al. 2017a). A number of individual comparisons of LES to each other (Beare et al. 2006), and of SCM to LES (Bosveld et al. 2014; Svensson et al. 2011), have been undertaken and have proven useful. Neggers et al. (2012) implemented a continuous system for running and comparing single-column models and LES. LASSO adds a large and growing library of shallow cumulus cases over land at the ARM Southern Great Plains site (Sisterson et al. 2016). Such comparisons are sensitive to the initial and boundary conditions and advection terms supplied to the LES or SCM (Baas et al. 2010; Basu et al. 2008). LASSO addresses this issue by using several different large-scale forcing datasets for each case day, thus promoting the exploration of the space of possible "correct" solutions. Discussion of these issues can also be found in Heinze et al. (2017).

For this study, we chose three simulations for each of the five days of the LASSO Alpha 1 release (Gustafson et al. 2017b). The simulations we chose have initial conditions, surface forcings, and advective forcings from the same analysis for each simulation (Table 1). All of the simulations we chose were run with the WRF LES. In choosing these simulations from the many available for each day, we were looking for a range of results, not necessarily for the "best" simulation by any particular criteria. The comparisons that follow are made to the LES, not to observations directly; however, we do show 
TABLE 1. Simulation identification and source of large-scale advective forcings, initial conditions, and surface forcings for the simulations chosen for this study. Note that the Jun $(6,9$, and 27 Jun) and Aug (1 and 29 Aug) case days have different simulation identifiers.

\begin{tabular}{cccll}
\hline \hline $\begin{array}{c}\text { SIM_ID } \\
\text { (Jun) }\end{array}$ & $\begin{array}{c}\text { SIM_ID } \\
\text { (Aug) }\end{array}$ & \multicolumn{1}{c}{ Forcing } & \multicolumn{1}{c}{$\begin{array}{c}\text { Initial } \\
\text { condition }\end{array}$} & \multicolumn{1}{c}{ Surface } \\
\hline 30 & 26 & VARANAL & VARANAL & VARANAL \\
31 & 27 & MSDA & MSDA & MSDA \\
34 & 30 & ECMWF & ECMWF & ECMWF \\
\hline
\end{tabular}

sounding profiles and liquid water path observations where they are available. Correspondence between LES and observations will be the subject of forthcoming reports and publications from the LASSO team. However, various metrics of the LES with respect to observations are computed and displayed on the LASSO website. The WRF LES runs were selected because we were already familiar with WRF output formats. Table 1 shows the simulation identifiers and the forcings for each. The forcing analyses are described in Gustafson et al. (2017c), here we mention them very briefly. Variational analysis over a $300-\mathrm{km}$ region (VARANAL) starts from the operational Rapid Refresh analysis (Hu et al. 2017) and uses ARM and other observations. ECMWF is an analysis derived from forecasts made by the European Centre for Medium-Range Weather Forecasts, representing an area $413 \mathrm{~km}$ on a side. The multiscale data assimilation (MSDA) technique uses WRF simulations driven by a multiscale data assimilation technique (Li et al. 2015a,b). The MSDA simulations chosen here represent an area $300 \mathrm{~km}$ on each side. The advective forcings include vertical motion (subsidence), temperature, humidity, and geostrophic wind.

\section{Single-column model setup and issues}

The WRF single-column model capability was described by Hacker and Angevine (2013). It allows for initialization of the model with specified temperature, humidity, and wind profiles. During the run, advective tendencies are implemented by relaxing the model on specified time scales. Two time scales are available. For this work, only the so-called large-scale tendencies are used. The relaxation time scale is set to the model time step, so the tendencies exactly follow those specified. The profile quantities by which the SCM is driven are geostrophic wind, subsidence (vertical velocity), temperature, and water vapor (specific humidity). At the surface, the model can be forced by specified sensible heat flux, latent heat flux, and skin temperature. Alternatively, the model can be run with an interactive land surface. Other issues with SCM forcing are discussed by, for example, Tang et al. (2017).

The surface forcing deserves further exploration. WRF is normally used in a coupled mode, wherein the surface layer scheme, land surface scheme, and PBL scheme are called in that order during each time step. The surface layer scheme computes exchange coefficients, similarity variables, and friction velocity $\left(u^{*}\right)$, which differ for each surface layer and PBL-scheme combination. The land surface scheme then computes the terms of the surface energy budget, including sensible and latent heat fluxes and skin temperature. These quantities are not independent; they are coupled through the effective stability functions coded into the surface layer land surface schemes. So, for example, the skin temperature, temperature at the first atmospheric model level, and $u^{*}$ determine the sensible heat flux in the normal coupled configuration. To run idealized simulations, we often choose to specify several of these quantities. There is a risk that the specification, derived from some particular model, may not be consistent with the parameterized physics within the SCM (or LES). In this study, for the basic runs with the MYNN-EDMF scheme, we force the heat fluxes and skin temperature. The MYNN surface layer scheme computes $u^{*}$. The MYNN PBL scheme does not make use of the skin temperature; instead it uses the Obukhov length $L$. Because the skin temperature provided to the surface layer scheme is not necessarily consistent with the heat flux and first-level temperature, $L$ is recomputed in the surface driver at each time step. The surface forcing, including this recalculation, is done by custom code in the surface driver, not part of the regular WRF release package.

To explore the implications of this possible surface forcing inconsistency, we also execute "coupled" runs, wherein the Noah land surface model is called to provide surface fluxes, and the provided fluxes and skin temperature are not used. The results are generally similar between coupled and uncoupled (surface forced) runs; important differences will be described below. All of the TEMF runs are coupled.

The vertical grid for most of the runs shown here is approximately that used for the operational Rapid Refresh and High Resolution Rapid Refresh models. It has 51 levels, compressed near the ground and near the tropopause (see the appendix). The lowest level is approximately $7.7 \mathrm{~m}$ AGL and the model top is at approximately $14.6 \mathrm{~km}$ AGL. In the cloud layer of these simulations, at $2000 \mathrm{~m}$ AGL, the layer thickness is $387 \mathrm{~m}$, and at $5000 \mathrm{~m}$ AGL, the layer is $518 \mathrm{~m}$ thick. This relatively coarse grid plays a role in the results shown later. For TEMF, we use a 64-level grid with more levels in the 
cloud layer, since this is more similar to the grid that an ordinary research user of WRF might use.

\section{Results}

First we show the results for one simulation on multiple days. The simulation chosen uses the VARANAL forcings (Table 1). We focus on cloud properties. Cloud base depends on the subcloud temperature and water vapor. Cloud top depends on the updraft lateral entrainment rate, and the balance of momentum between deceleration due to the increasing environmental temperature and latent heat release in the updraft. The liquid water content depends on the small difference between total water and saturation water vapor in the updraft, and is a sensitive indication of the amount of cloud. Cloud fraction and liquid water in each model layer together determine the effect on radiation. For simplicity, we primarily show the vertically integrated liquid water (LWP) and maximum cloud fraction in any layer (cloud cover).

LWP in the LES varies by an order of magnitude between the extremes of 9 June and 29 August (Fig. 1). During the part of the day when clouds are active (roughly 1200-1600 CST), the SCM captures the variation. During the active part of each day, the mass-flux component accounts for almost all of the cloud (massflux part and total are equal). Late in the day on 9 June and 1 August, the nonconvective subgrid cloud is active, and produces large cloud fractions within the boundary layer, which are not seen in the LES. On 29 August, only the nonconvective subgrid cloud part produces cloud, which is somewhat overestimated but still quite tenuous. Cloud cover varies much less from day to day than LWP, and is well captured during the active part of all days except 29 August. Cloud base and top are visibly affected by the coarse SCM vertical grid, but generally follow the LES well. On all days except 1 August, the SCM forms cloud earlier than the LES, but this early cloud is very thin and tenuous.

Vertical profiles at roughly the time of peak cloud activity from the same simulations are shown in Fig. 2. Generally the SCM potential temperature profiles match the LES well, with different small errors on different days. There is a general tendency for the SCM to be too moist near the surface and too dry aloft, with $q$ profiles less well mixed than in the LES. This may indicate that the mass-flux contribution is too weak. Less mixing is needed to produce well-mixed profiles of temperature than for water vapor, because the surface flux and entrainment flux (top) of heat both tend to warm the layer, while the fluxes for water vapor often tend to moisten the layer at the bottom and dry it at the top (Cancelli et al. 2014; Larsen et al. 2014). Further research on this issue is needed.

Figure 2 also includes radiosonde profiles at 2030 UTC for the three days on which they were available. Observed potential temperature is warmer than modeled by either LES or SCM in the subcloud layer. On 6 June, the observed boundary layer (including the cloud layer) is shallower than either type of model, on 9 June it is deeper, and on 27 June it is about the same. Observed subcloud layer moisture is greater on 6 June, less on 9 June, and about the same on 27 June as in the models. The observed inversion at the PBL top is sharper than in the models. In general the SCM and LES agree better than either type of model agrees with the observations. This is not surprising, since the models are driven by the same initial, surface, and advective forcings.

Different large-scale forcings produce quite different solutions in both LES and SCM for the same day. Figure 3 shows the cloud properties for 6 June using the three large-scale forcings shown in Table 1. The VARANAL simulation is the same as the top row of Fig. 1. It has robust clouds and a good match between LES and SCM. The MSDA simulation has almost no cloud in the LES. The nonconvective subgrid cloud part of MYNN-EDMF produces a small amount of cloud in the middle of the day. The simulation from the ECMWF analysis has an intermediate amount of cloud. The cloud starts early in the SCM, and is too deep (low base and high top) until about 1100 CST, but with nearly no liquid water path. The mass-flux part cuts off early, around 2100 UTC, and the nonconvective subgrid part takes over. That part of the code reproduces the deep but relatively tenuous cloud layer that extends to the surface in the LES, albeit with imperfect timing.

The vertical profiles (Fig. 4) for these three simulations on 6 June are instructive in understanding the differences in cloud properties that arise from the different forcings. Liquid water content is also shown on the water vapor plots. The LES, with its relatively fine grid, has smooth profiles, including those of liquid. The SCM potential temperature and water vapor profiles are not smooth. Liquid profiles are well represented considering the coarse SCM grid. This is encouraging given the inability of the SCM to fully capture the moisture profile in the upper half of the boundary layer. Compared to the observed sounding (note that it is the same in all rows of the figure), we see that the simulations with VARANAL have a PBL that is too deep, those with MSDA are too shallow, and the ECMWF forcings give a reasonable PBL depth but with temperatures that are too cool. Again, the LES and SCM simulations for each forcing are more similar to each other than to the 
MYNN VARANAL
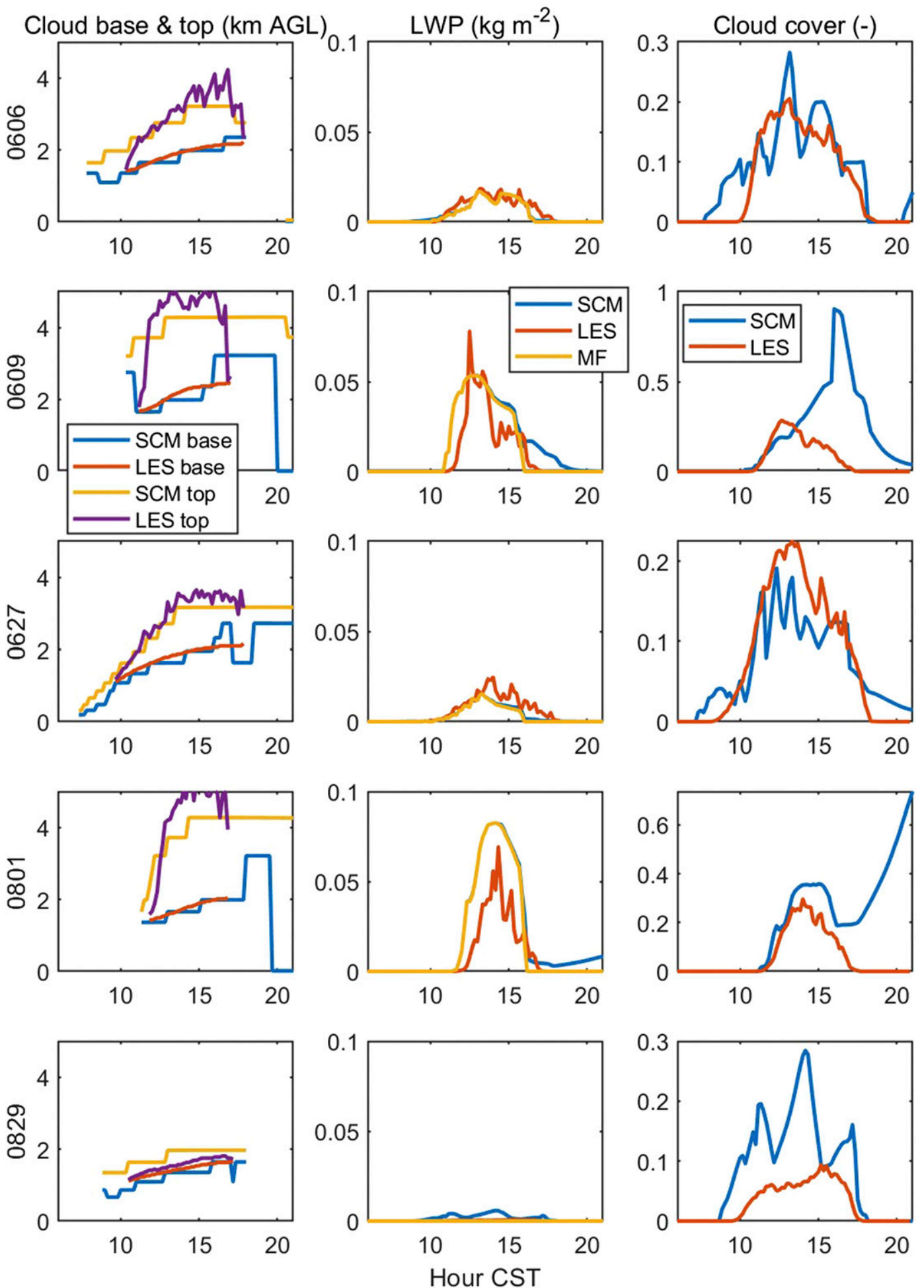

FIG. 1. Cloud properties in the LES and MYNN-EDMF SCM (51 levels, uncoupled) for one simulation on five days (rows labeled on the left). Cloud base and top (m), liquid water path $\left(\mathrm{kg} \mathrm{m}^{-2}\right)$, and cloud cover (unitless) are shown in columns as labeled. Line colors are called out in the legend. Note that vertical axes for cloud cover differ for each day. In the LWP plots, the contribution from the mass-flux component is shown in yellow, and the total including nonconvective subgrid cloud is in blue. 
MYNN VARANAL
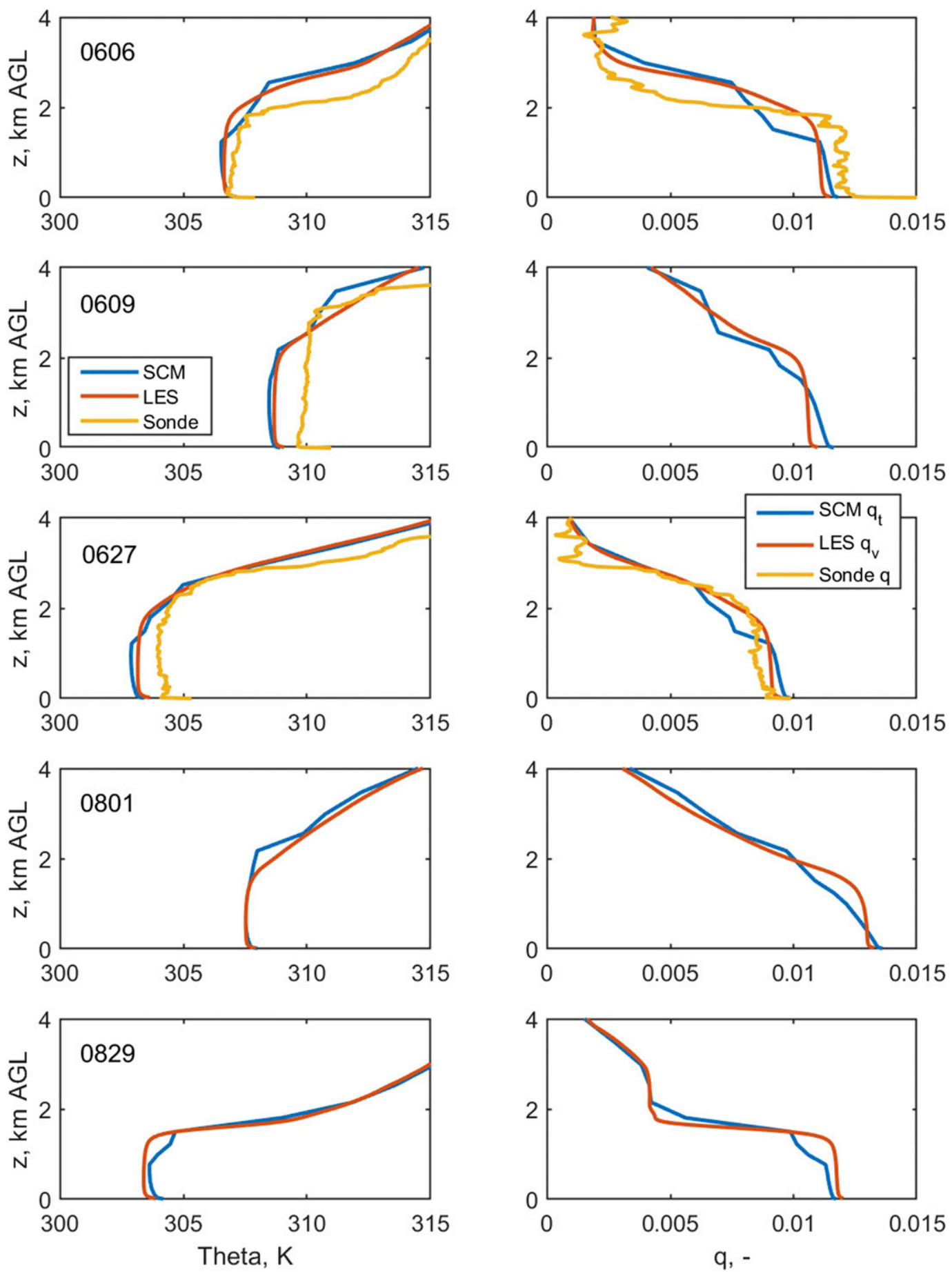

FIG. 2. Potential temperature and specific humidity profiles for the same simulations shown in Fig. 1, at time 1430 CST. LES profiles (domain averaged) are in red, SCM in blue. Radiosonde profiles at the same time are shown for the three days for which they are available; moisture profile on 9 Jun is of poor quality and not shown. 


\section{MYNN}
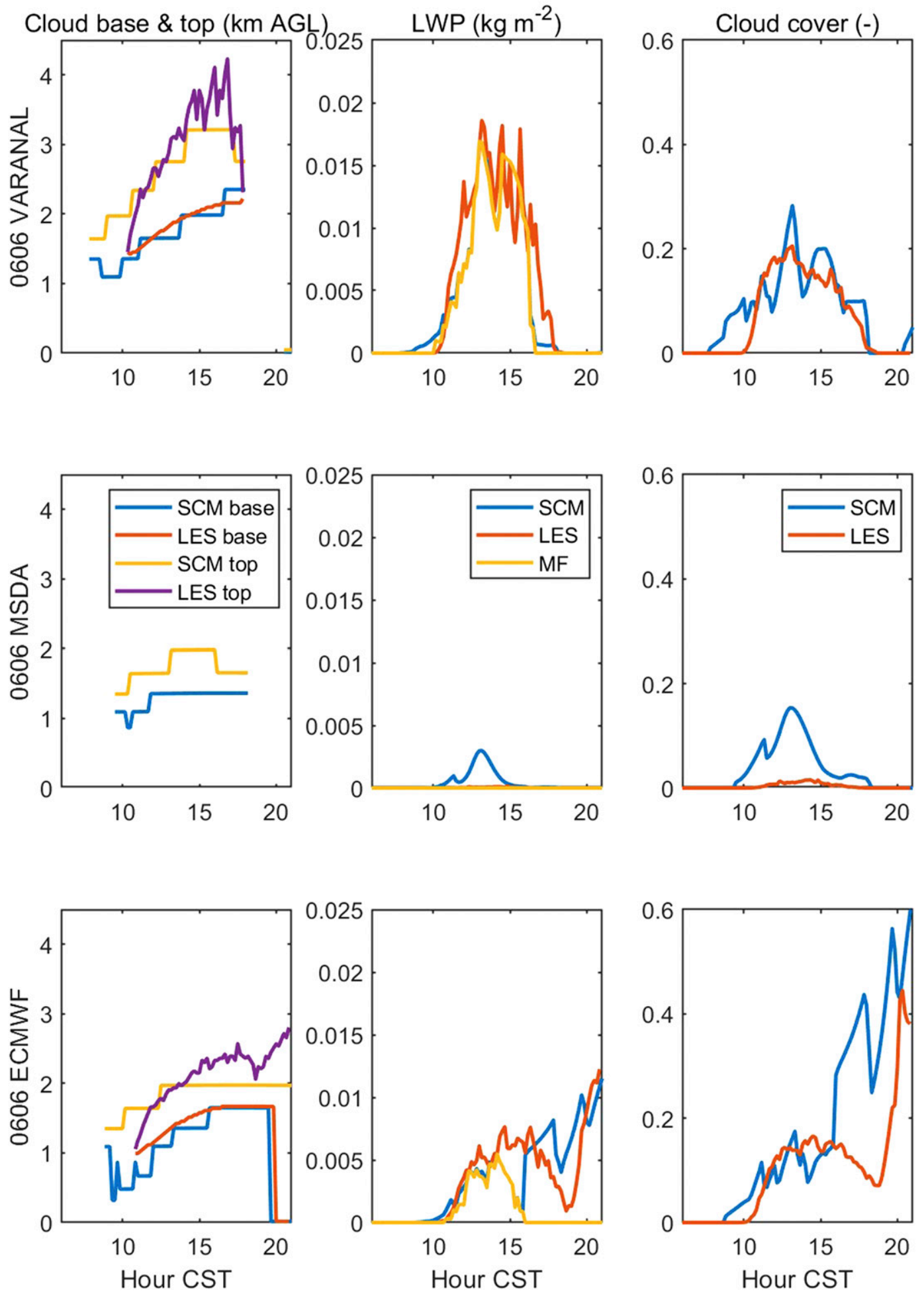

FIG. 3. Cloud properties in the LES and SCM (uncoupled) for three simulations (forcings as labeled on the left) on one day (6 Jun 2015). Cloud base and top (m), liquid water path $\left(\mathrm{kg} \mathrm{m}^{-2}\right)$, and cloud cover (unitless) are shown in columns as labeled. Line colors are called out in the legend. In the LWP plots, the contribution from the mass-flux component is shown in yellow, and the total including nonconvective subgrid cloud is in blue. 


\section{MYNN}
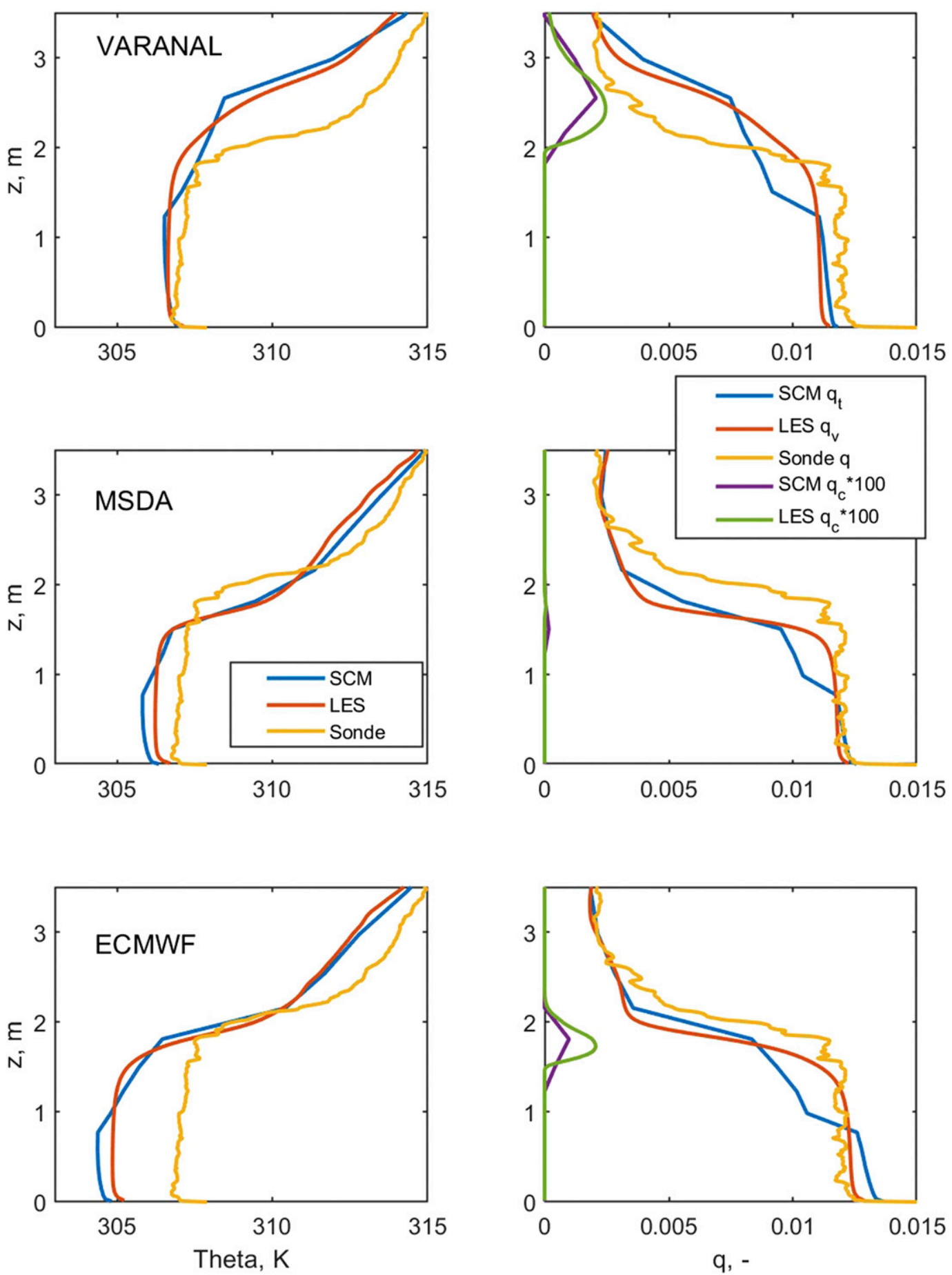

FIG. 4. Potential temperature and specific humidity profiles for the simulations shown in Fig. 3, at time 1430 CST. LES profiles are in red, SCM is in blue, and 2030 UTC sounding is in yellow (same sounding for all three rows). In the right column, liquid water content $\left(\mathrm{kg} \mathrm{kg}^{-1} \times 100\right)$ is also shown, with the LES in green and SCM in purple. 


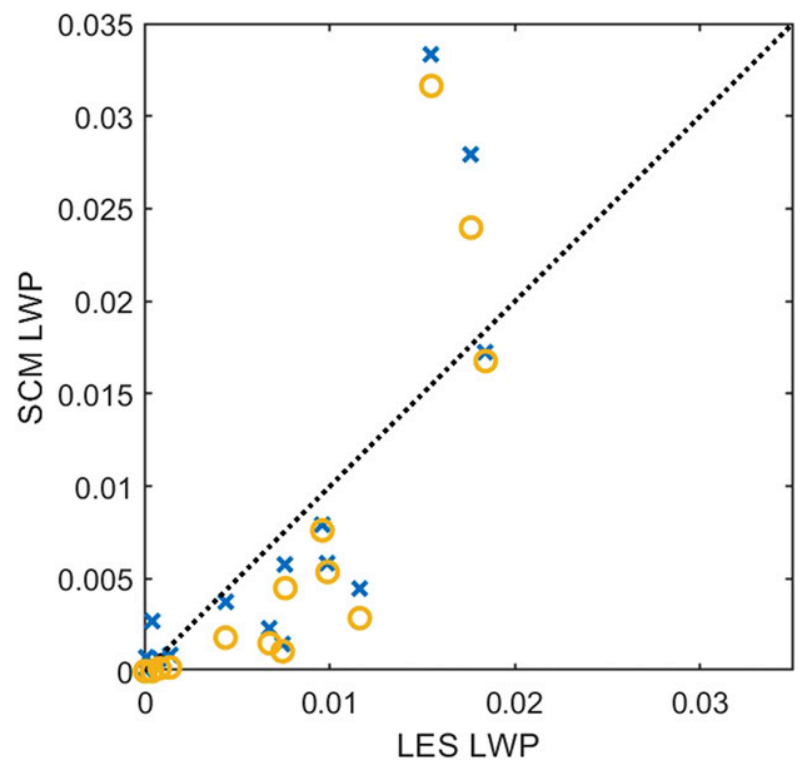

FIG. 5. Mean liquid water path $\left(\mathrm{kg} \mathrm{m}^{-2}\right)$ for the uncoupled MYNN-EDMF simulations with three different forcings for each of the five days. Mean is taken over 1000-1800 CST . Blue $\times$ s include nonconvective subgrid cloud and gridscale cloud, and yellow circles are the mass-flux cloud only.

observations, affirming the importance of the forcing to the simulated solution. On the other four days, the three simulations exhibited similar relative behavior, so we do not show them here.

A quantitative evaluation of the liquid water path is shown in Fig. 5. The LWP for the three simulations on each day is averaged over 1000-1800 CST, approximately the period of active cloud. Cloud liquid due only to mass flux (yellow) is shown separately from the total of all three cloud processes (blue). The LES and SCM LWP covary substantially, although the mass flux alone represents the LES slightly better. Correlation coefficients between the SCM and LES LWP are 0.82 for mass-flux cloud and 0.81 for total cloud. The worst performance for the total is the overestimate on $1 \mathrm{Au}-$ gust (uppermost points in the figure), as has already been noted. This figure is for the uncoupled runs (specified surface fluxes), the coupled runs perform similarly but are not shown.

Liquid water path observations were obtained from the AERIoe retrieval, which combines ground-based infrared [Atmospheric Emitted Radiance Interferometer (AERI)](Knuteson et al. 2004) and microwave radiometer (Cadeddu et al. 2013) measurements (Turner and Loehnert 2014; Turner and Blumberg 2018) using an optimal estimation approach. The combination of the AERI and MWR radiances in a single retrieval results in a significantly more accurate LWP retrieval over the entire range of LWP (Turner
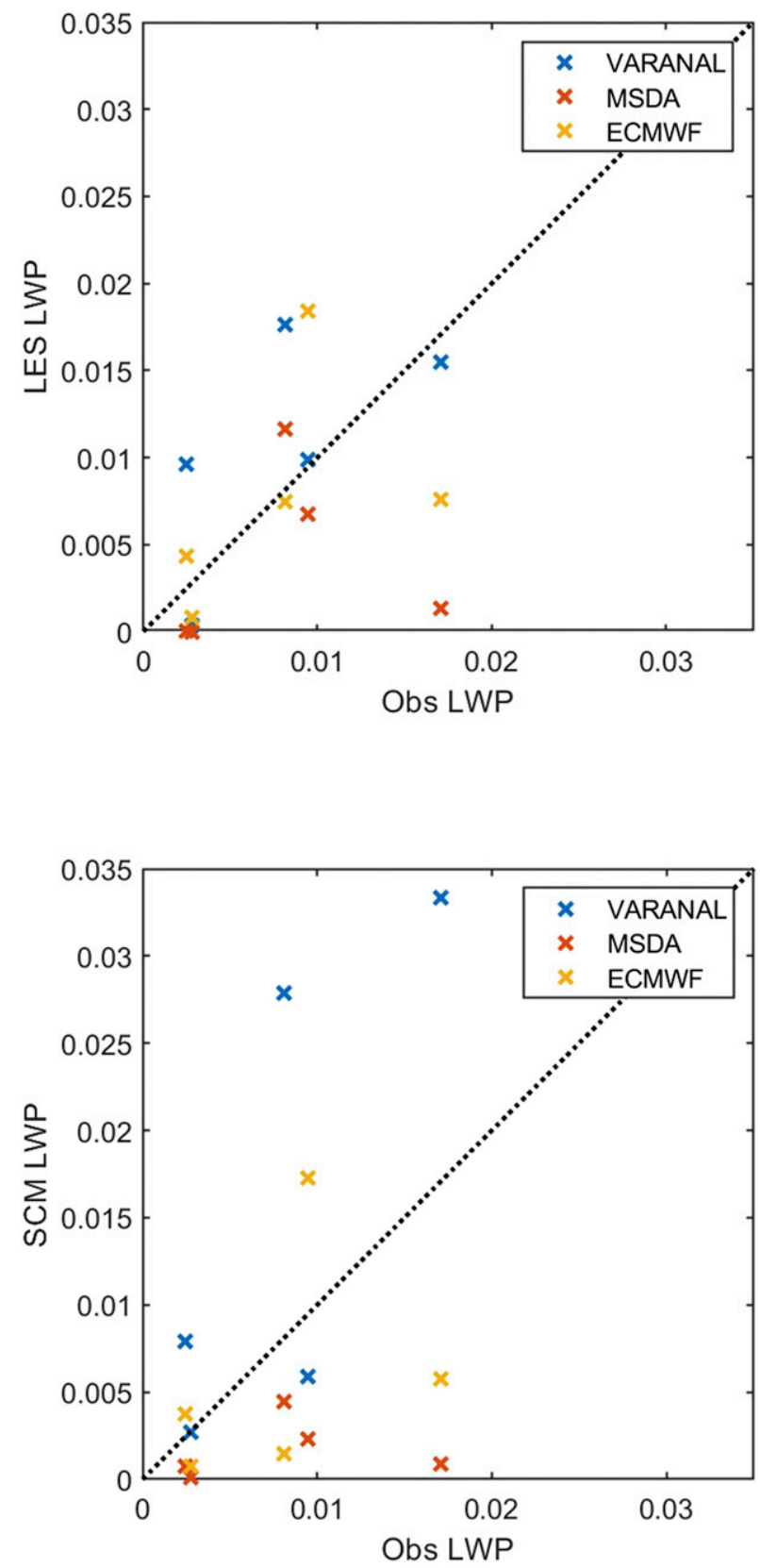

FIG. 6. Observed liquid water path from the AERIOE retrieval vs (top) LES and (bottom) SCM LWP. Domain-averaged LWP is averaged over 1000-1800 CST for each day. The three forcings are color coded as shown in the legends. Note that there are only five unique $x$-axis locations (the observed LWP for each of the five days).

2007). In-cloud LWP estimates were produced every 20 s, each with an uncertainty estimate. In Fig. 6, we show averages of the observed LWP over the active part of the day (1000-1800 CST) plotted against values from the LES and SCM. The observed in-cloud LWP is averaged to $1 \mathrm{~h}$ and multiplied by the corresponding houraverage low cloud fraction from the ARM value-added 
product Active Remote Sensing of Clouds (ARSCL; Clothiaux et al. 2000) to produce values that can be compared to the domain-averaged LWP from the LES and SCM. The AERIoe 20-s uncertainty estimates are approximately $4 \%$ of the LWP value. The true uncertainty of the LWP is certainly dominated by sampling uncertainty, given the small beamwidth of the instruments and the small cloud fractions relevant here. We do not attempt to estimate that uncertainty.

The three LES-simulated LWP values for each day (Fig. 6, top) bracket the observations on three of the five days. The importance of the forcing, previously noted, is reinforced by the wide spread in the vertical direction for each observed value. No single forcing is superior on all days (Gustafson et al. 2017a). The spread of SCM values is even greater (Fig. 6, bottom), with the result that the simulations bracket the observations on all five days.

\section{Discussion}

The MYNN-EDMF scheme was substantially tuned to the 6 June VARANAL case only. More than 100 SCM simulations of that case were run, and various parameters and formulations in the scheme were tuned. However, the tuning was also directed by the primary forecast objectives of the operational RAP/HRRR for which the scheme is intended, such as severe convection, near-surface temperatures, and cloud ceilings. Those models run on very extensive domains, and must faithfully represent clouds from the tropics to the Arctic. As such, considerable effort was expended to make sure that the mass-flux part of the scheme was not too active, which would deteriorate the representation of gridscale or subgrid stratus.

Forcing SCM runs with surface fluxes and skin temperature incurs some uncertainty, as discussed above. To make sure that the differences between LES and SCM are due to the PBL and shallow cloud formulation in the SCM, and not to ambiguity in the surface forcing, we executed the same simulations with a coupled land surface, still with the MYNN-EDMF PBL scheme. The Noah land surface model (LSM) was used, with land type 2 (dryland cropland and pasture), soil type 7 (sandy clay loam), and green vegetation fraction 0.9 . For each simulation, all soil layers were initialized to the temperature of the surface in the input sounding. Soil moisture was tuned to produce as closely as possible the peak fluxes and their partitioning as specified to the LES. This tuning was in a narrow range between 0.27 and 0.32 (relative soil moisture fraction), uniformly for all soil layers.

Figure 7 shows the cloud properties from the coupled runs for the VARANAL simulations on each of the five days. Comparing these to the uncoupled runs in Fig. 1, we see that the coupled runs produce slightly more
LWP, especially later in the run. On 27 June this is an improvement, but on 6 and 9 June it matches the LES less well. Fog (cloud base at the surface) is not present late in the coupled runs for 9 June and 1 August, as it was in the uncoupled runs, but large cloud fractions aloft are still present. In Fig. 8, the surface fluxes specified in one of the uncoupled runs and produced by the land surface model are compared. The LES is driven by the same fluxes as the uncoupled SCM. Note that the friction velocity $u^{*}$ is not specified in either case. The peak sensible and latent heat fluxes are similar between the specification and the LSM, due to soil moisture tuning. The fluxes produced by the LSM with either PBL scheme are slightly lower early and slightly higher late in the run, which probably accounts for the slight timing shift in LWP. The coupled sensible heat flux after 18.5 CST is slightly negative, as expected for this time of day, but the specified flux is strongly negative. This is responsible for the formation of fog in the uncoupled runs, as the strong negative sensible heat flux forces the near-surface layers to cool and stabilize, which limits upward transport of the water vapor introduced by the still-positive latent heat flux. Skin temperature in the coupled simulation is higher than that specified.

Tenuous cloud presents a challenge to the MYNNEDMF parameterization. As can be seen for the 6 June MSDA simulation (Fig. 3) and the 29 August VARANAL (Fig. 1), clouds that barely exist in the LES are not well simulated by the mass-flux part of the scheme. This is an expected result of using discrete updrafts.

The vertical grid for these MYNN-EDMF experiments was similar to that used on the RAP and HRRR. This constrained the cloud liquid to one or two levels and we hypothesized that it might have contributed to the nonsmooth profiles. However, the overall results in terms of LWP and cloud cover were still reasonable. Uncoupled simulations with a finer grid of 64 levels (see the appendix) contradicted this hypothesis. The main points of behavior were similar, including fog in 9 June and 1 August VARANAL simulations. LWP was smaller. Cloud base was too low, and the vertical profiles remained unsmooth. Overall the finer-grid simulations did not show improved results. It is likely that some retuning of the scheme would be needed to demonstrate better results with a finer grid. Finer resolution would likely be more important for stratocumulus conditions, which have thin cloud layers under sharp inversions, than for these relatively deep "shallow" cumulus conditions.

The sensitivity of cloud properties to two parameters in the MYNN-EDMF scheme is tested here. This is by no means a complete evaluation of the parameter space, but a simple demonstration of how sensitive the scheme is to two parameters we expected a priori to be important. 


\section{MYNN coupled}
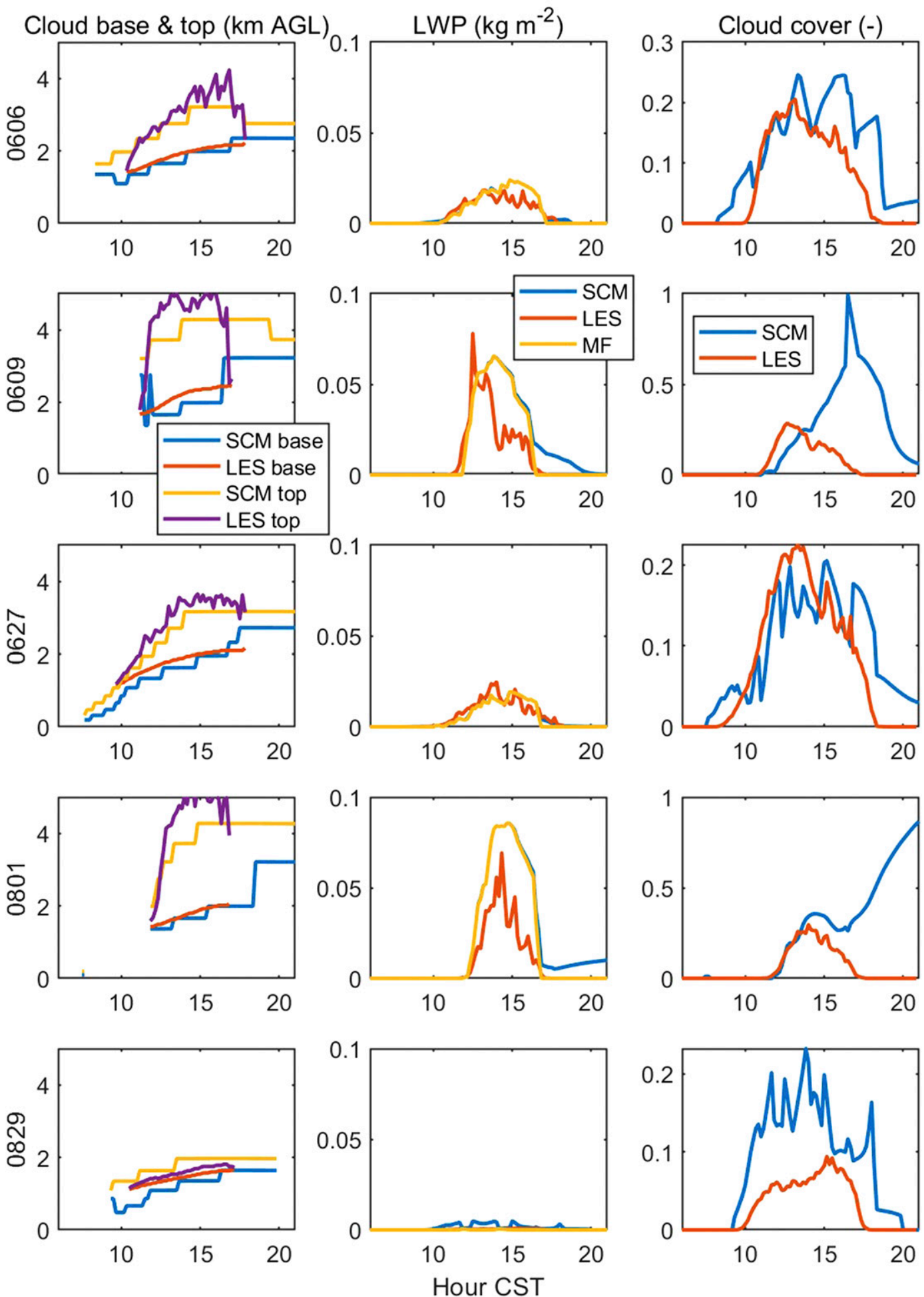

FIG. 7. Cloud properties in the LES and SCM coupled to the land surface for one simulation on five days. Cloud base and top $(\mathrm{m})$, liquid water path $\left(\mathrm{kg} \mathrm{m}^{-2}\right)$, and cloud cover (unitless) are shown in columns as labeled. Line colors are called out in the legend. Note that vertical axes differ for each day. In the LWP plots, the contribution from the mass-flux component is shown in yellow, and the total including nonconvective subgrid cloud is in blue. 

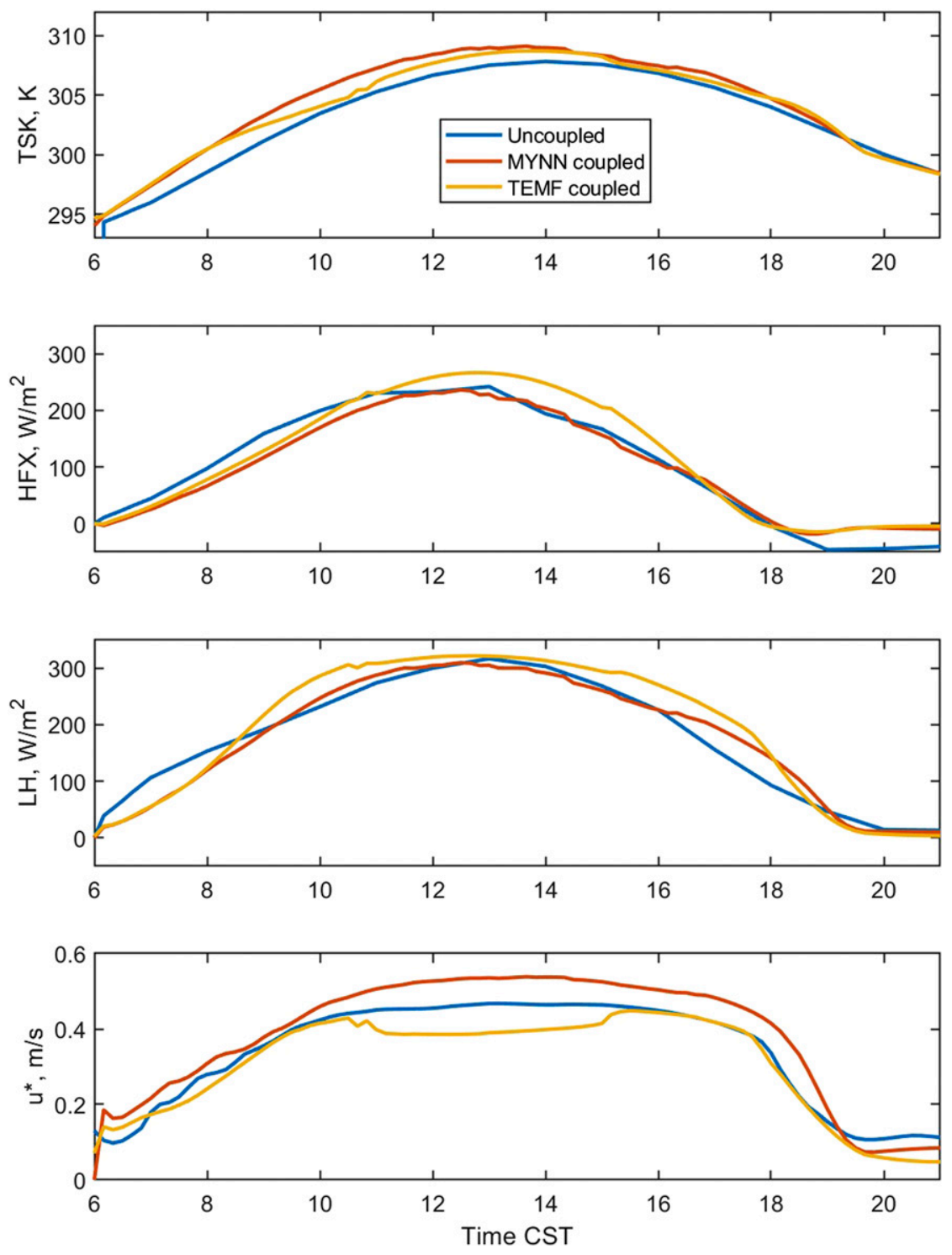

FIG. 8. Surface temperature and fluxes in uncoupled (blue), MYNN coupled (red), and TEMF coupled (yellow) SCM simulation of 6 Jun VARANAL (sim0030). In the uncoupled run, the fluxes (except $u^{*}$ ) are specified to the SCM and LES. In the coupled runs, the fluxes are produced by the Noah land surface model.

More complete evaluations of MYNN parameters in an earlier (non-EDMF) version are presented by Yang et al. (2017). The chosen parameters are the leading coefficient of the lateral entrainment rate equation (AEPS $=0.5$ ) and the coefficient $B$ in the updraft vertical velocity calculation $(\mathrm{BCOEFF}=0.2$; see the appendix). AEPS controls how much environmental air the updraft entrains as it rises, and therefore how much the updraft properties tend toward the enviroment's properties. BCOEFF controls how much the updraft is accelerated or decelerated by the buoyancy difference between the updraft and environment. In MYNN-EDMF, BCOEFF is set separately for positive and negative buoyancy. We choose a small range for the tested changes (approximately plus or minus $10 \%$ of the parameter's central value) to make sure that the system stays in the same basic regime and does not encounter other limits. The chosen values are tabulated in Table 2. See the appendix for details of the formulations.

Decreasing lateral entrainment into the updraft by reducing AEPS increases LWP throughout the run (Fig. 9), and increasing entrainment reduces LWP. This is the first-order control in any EDMF scheme (e.g., Angevine et al. 2010) and the effect is strong for even 
TABLE 2. Parameter values for sensitivity tests. BCOEFF values were varied as pairs (accelerating and decelerating together, see the appendix), not separately, for a total of four sensitivity tests.

\begin{tabular}{lccc}
\hline \multicolumn{1}{c}{ Parameter } & Central & Smaller $(-)$ & Larger $(+)$ \\
\hline AEPS & 0.50 & 0.45 & 0.55 \\
BCOEFF accelerating & 0.15 & 0.135 & 0.165 \\
BCOEFF decelerating & 0.20 & 0.18 & 0.22 \\
\hline
\end{tabular}

this small change in the coefficient. Changing the updraft acceleration due to buoyancy has a weaker effect. Reducing BCOEFF by $10 \%$ reduces LWP late in the run, and increasing BCOEFF has the opposite effect. The LWP change is partly due to a corresponding change in cloud thickness (not shown). Because changing BCOEFF for both acceleration and deceleration together has a compensating effect, we did not have specific a priori expectations for this change.

As a comparison with a simpler scheme, cloud properties from the TEMF PBL scheme are shown in Fig. 10. This scheme has only one source of subgrid cloud, the condensing (single) updraft. It is run on the 64-level grid, coupled to the LSM. Some parameters have been modified from the version contained in recent WRF releases to achieve the results shown here; this tuning was done on the 6 June VARANAL case only. The cloud base and cloud top compare well to the LES, although the timing is imperfect. Liquid water path and cloud cover also agree well during the period of active convection. Overall TEMF LWP is lower and less variable than in the LES. Updraft lateral entrainment in TEMF depends only on the height reached by a dry test updraft (see the appendix), and the flux limiter also plays a role in reducing the ability of the scheme to vary LWP. The MSDA forcing produces very tenuous clouds in these runs as it did in the MYNN runs. In the ECMWF-forced run, the increase in cloud cover late in the day seen in the LES is not seen in the TEMF SCM run, which has no ability to produce subgrid cloud when the surface is stable. The fluxes in the coupled TEMF 6 June VARANAL run are shown in Fig. 8.

Potential temperature and specific humidity profiles presented in Fig. 11 are considerably smoother with TEMF than with MYNN-EDMF (Fig. 4). We suspect that this is due to increased eddy diffusivity in the cloud layer, in turn caused by the use of total turbulent energy (TE) rather than TKE as the prognostic energy variable in TEMF. TE is not destroyed by stable stratification, so it is carried higher into the stably stratified cloud layer. This hypothesis will be a subject of future work. The profiles also show a lower subcloud layer height and a less wellmixed humidity profile than in the LES. The relationship between the simulated and observed profiles is similar to

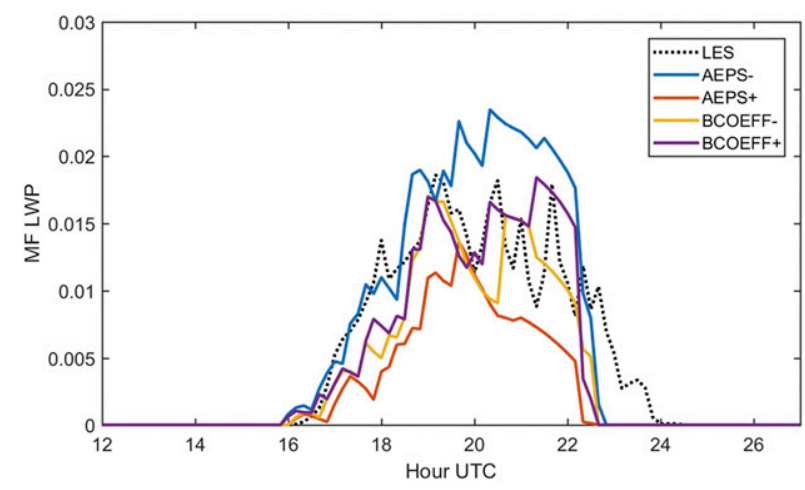

FIG. 9. Liquid water path in sensitivity test runs. See Table 2 for labels and values of modified parameters.

the MYNN-EDMF results; again, the simulations are more similar to each other than to the observations.

Compared to the version contained in recent WRF releases (up to v3.9), the following changes were made to improve the performance of TEMF for this study. The updraft specific humidity is initialized with the surface value rather than the first model level value. The firstguess height of the updraft is calculated as the height where virtual potential temperature first exceeds the average of the values at the lowest two levels, rather than the lowest level only. The mass-flux contribution to heat flux at the lowest level is now imposed relative to the surface flux rather than to the eddy diffusivity flux at the first level, considerably strengthening the mass-flux contribution. A new limit of $2.0 \mathrm{~m} \mathrm{~s}^{-1}$ on maximum updraft vertical velocity is imposed. A former lateral entrainment limit of $0.002 \mathrm{~s}^{-1}$ minimum was removed. Overall these changes increase the height to which the updraft rises and the amount of moisture it carries aloft, thereby increasing cloud top and LWP. These changes can be seen in the code provided and in the code fragments in the appendix. We have no immediate plans to include them in a WRF release.

\section{Conclusions}

The new MYNN-EDMF scheme for boundary layer mixing and cloud performed very well in these singlecolumn tests. Its performance was evaluated against LES of several different case days. For each day, there were three different forcing datasets, which consist of initial conditions, advection terms, and surface fluxes. Liquid water path, cloud fraction, and cloud base and top heights compared well. The cases provided a wide range of LWP, which was reproduced well by the SCM during the convectively active periods. One notable difference was seen late in the day on 9 June and 29 August, when the SCM produced large cloud fractions not seen in the LES. 

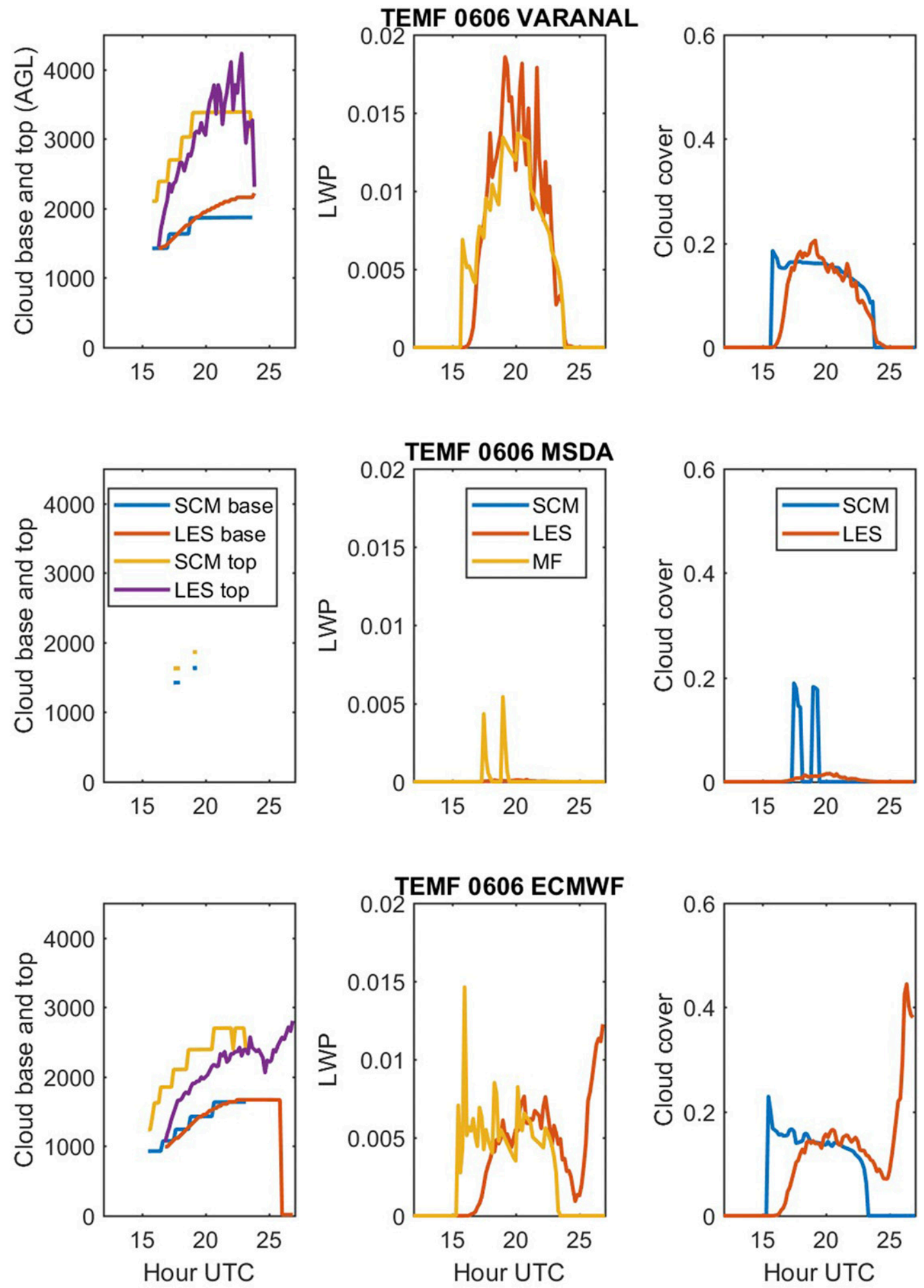

FIG. 10. Cloud properties in the LES and SCM with TEMF PBL scheme coupled to the land surface for three simulations on one day (6 Jun 2015). Cloud base and top (m), liquid water path ( $\left.\mathrm{kg} \mathrm{m}^{-2}\right)$, and cloud cover (unitless) are shown in columns as labeled. The three different forcings are in rows. Line colors are called out in the legend. In the LWP plots, the contribution from the mass-flux component is shown in yellow, which is the only source of subgrid cloud in this scheme. 
TEMF 0606
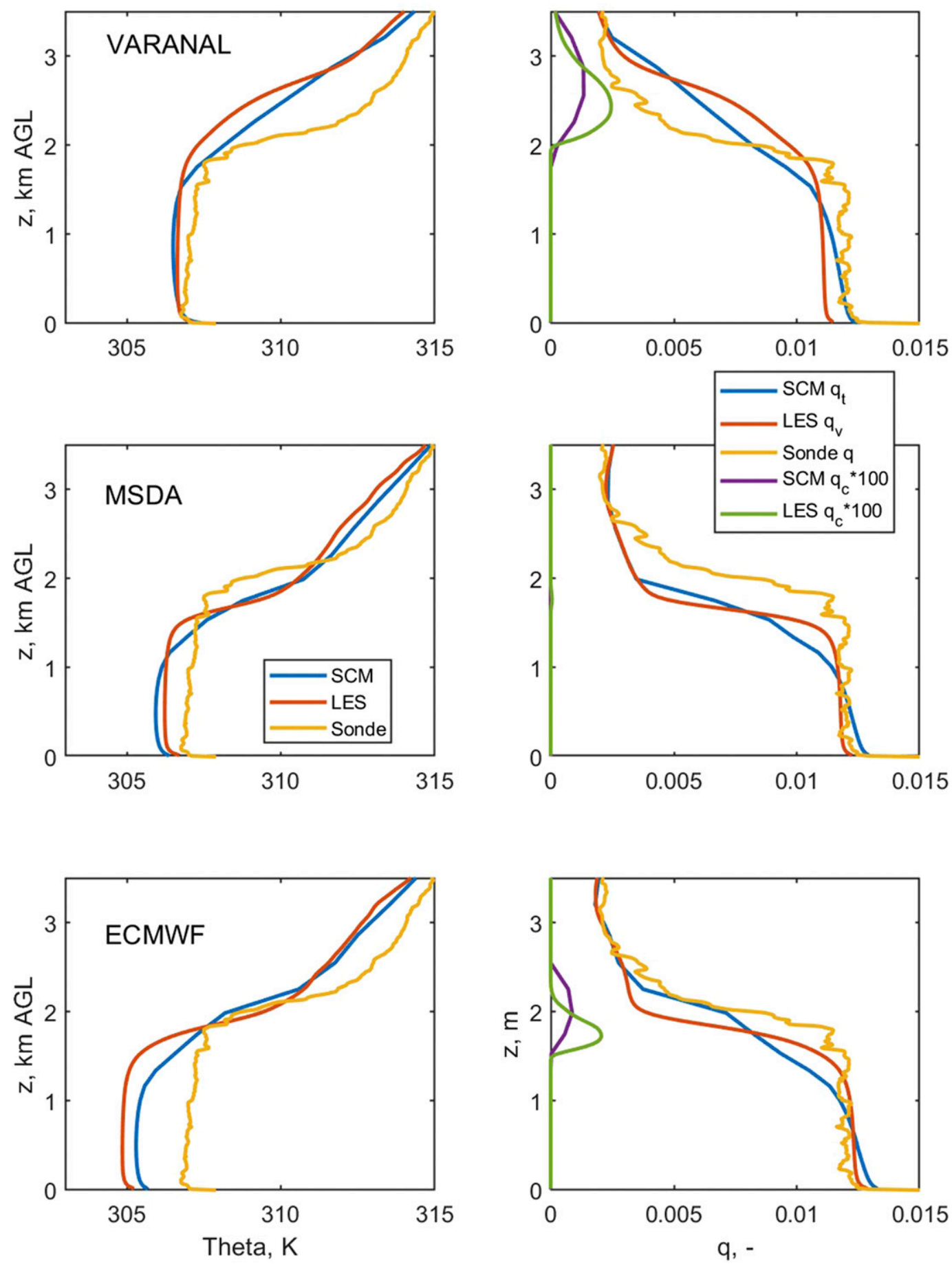

FIG. 11. Potential temperature and specific humidity profiles for the simulations shown in Fig. 10, at time 1430 CST. LES profiles are in red, SCM is in blue, and 2030 UTC radiosonde is in yellow. In the right column, liquid water content $\left(\mathrm{kg} \mathrm{kg}^{-1} \times 100\right)$ is also shown, with the SCM in purple and LES in green. 
On 29 August, when the LES cloud was very weak and tenuous, the nonconvective subgrid part of the SCM produced more and thicker cloud with more LWP, but still quite small compared to other days. Moisture profiles were not well-mixed, probably because of relatively weak mass-flux transport.

The vertical grid in the SCM was set to that used in the operational RAP/HRRR system, for which this scheme is intended. This resulted in some lack of smoothness in the temperature and moisture profiles, and in the cloud base and top. Cloud tended to occupy only one or two of the relatively thick $(\sim 500 \mathrm{~m})$ layers. However, this did not impair the overall good performance. Tests with a finer grid did not significantly improve the results.

Using specified surface fluxes to drive the SCM is a challenge independent of the actual performance of the SCM, since the effective flux-gradient relationships of the SCM and LES do not perfectly match. Runs with a coupled land surface model instead of specified fluxes produced quite similar results. This lends confidence that the MYNN-EDMF scheme performance shown here is robust and will carry over to full three-dimensional simulations.

This study contains a number of original contributions. It is the first use of the LASSO cases for parameterization development. The 15 cases shown are far more than shown in previous works, and allow us to consider how the boundary layer and shallow cloud schemes handle the variation in cloud amount from day to day and across different forcing data (e.g., Fig. 5). In addition, all previous works that include LWP use retrievals only from microwave radiometers (MWRs), and primarily from MWRs that only have channels at frequencies below $60 \mathrm{GHz}$. Retrievals that only use these low frequencies have very large uncertainties when the LWP is small. This is the first paper that uses the combined AERI + MWR, which has less than $20 \%$ random error over the entire range of LWP, to evaluate modeled $\mathrm{Cu}$. The MYNN-EDMF scheme is the first multiplume EDMF scheme to be used in an operational model in the United States.

The results shown here suggest several areas for future research. We will expand the analysis to include the LASSO Alpha 2 cases from 2016. We will evaluate the scale-aware aspects of the MYNN-EDMF scheme by using a multicolumn setup with varying grid spacing. This will inform analysis of the necessary number and distribution of updrafts. Further tuning of the nonconvective subgrid cloud calculation will be undertaken. Increasing eddy diffusivity in the cloud layer could make profiles smoother. The sensitivity of the scheme to the vertical grid should be explored and minimized. Strengthening of the mass-flux component to produce more well-mixed moisture profiles will be considered. Possible improvements to the simpler TEMF scheme

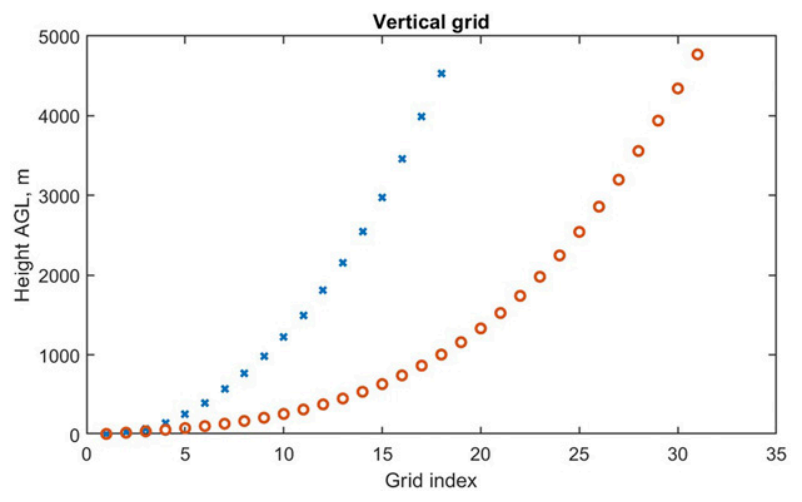

FIG. A1. Vertical grids used in the SCM simulations. Mass levels are shown. Only levels below $5000 \mathrm{~m}$ AGL are shown for clarity. Blue is the RAP/HRRR grid with 50 mass levels (51 namelist levels), red is the proposed future grid used in the TEMF simulations with 63 mass levels (64 namelist levels).

that can be tested with the LASSO framework may also be explored. The changes made here to TEMF may be considered for future WRF releases if they can be shown to be positive in a wider variety of cases.

Acknowledgments. This work was supported by the NOAA Atmospheric Science for Renewable Energy program. LASSO data are available at https://doi.org/10.5439/ 1256454, and more information can be found at https:// www.arm.gov/capabilities/modeling/lasso. Gustafson and Endo are supported by the DOE Office of Science Biological and Environmental Research via the Atmospheric Radiation Measurement Research Facility. Battelle Memorial Institute operates PNNL under Contract DEAC0576RL01830. Kay Suselj's research was carried out at the Jet Propulsion Laboratory, California Institute of Technology, under a contract with the National Aeronautics and Space Administration. Parts of his research were supported by the NASA MAP Program and the NOAA/CPO MAPP Program. The WRF SCM driving code, including scripts to convert forcings from LASSO, is available from https://esrl. noaa.gov/csd/groups/csd4/modeldata/. The version of the MYNN-EDMF scheme used here is available from the same URL. The provided code can be compiled with WRF, version 3.7.1. Modifications may need to be made to compile with earlier or later WRF versions.

\section{APPENDIX}

\section{Vertical Grid and Code Fragments}

Figure A1 shows the two vertical grids used for the runs described in this paper. 
Entrainment formulation: In MYNN-EDMF, the fractional entrainment rate is

$$
\begin{aligned}
& \operatorname{ENT}(k, i) \\
& \quad=0.5 /(\operatorname{MIN}\{\operatorname{MAX}[\operatorname{UPW}(K-1, I), 0.75], 1.5\} \times \ell),
\end{aligned}
$$

where $k$ is the level index, $I$ is the updraft index, UPW is the updraft vertical velocity, and $\ell$ is the plume diameter. The leading coefficient, denoted AEPS in the text $(0.5$ here $)$ is varied for the sensitivity tests (Table 2).

In TEMF, the fractional entrainment rate is

$$
\text { Cepsmf }=2.0 / \max [200 ., \mathrm{h} 0(i)],
$$

where h0 is the dry (test) updraft height and $i$ is the horizontal index. The rate is constant for all heights.

Vertical velocity equation:

In MYNN-EDMF

$$
\begin{aligned}
\mathrm{Wn}= & \mathrm{UPW}(K-1, I)+\{-2 . \times \mathrm{ENT}(K, \ell) \times \mathrm{UPW}(K-1, I)+\mathrm{BCOEFF} \\
& \times B / \operatorname{MAX}[\mathrm{UPW}(K-1, I), 0.2]\} \times \operatorname{MIN}[\mathrm{ZW}(k)-\mathrm{ZW}(k-1), 250 .],
\end{aligned}
$$

where Wn is the updraft velocity at level $K$, subject to further limits which can be examined in the code; and $B$ is the updraft buoyancy. BCOEFF is

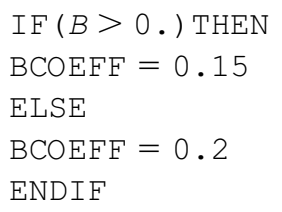

and is perturbed for the sensitivity tests with values shown in Table 2.

In TEMF, essentially the same formula is used, but with a fixed value of the $B$ coefficient:

$$
\begin{aligned}
& \text { dwUPDmoistdz }(i, k-1) \\
& \begin{aligned}
=-2 . \times \operatorname{epsmf}(i, k) \times \operatorname{wupd} \_t \operatorname{temfx}(i, k-1) \\
+0.33 \times \operatorname{Bmoist}(i, k-1) / \operatorname{wupd} \_t \operatorname{temfx}(i, k-1)
\end{aligned} \\
& \begin{aligned}
\text { wupd_temfx }(i, k)= & \text { wupd_temfx }(i, k-1) \\
& +\operatorname{dwUPDmoistdz}(i, k-1) \\
& \times \operatorname{dzm}(i, k-1)
\end{aligned}
\end{aligned}
$$

(De Roode et al. 2012) discuss the vertical velocity representation in models in great detail, and they find that the form of equation used in our two schemes and nearly all others has a questionable theoretical basis. They also tabulate coefficient values used in many schemes. In particular, they argue that the entrainment term is unsupported and that the optimal value of its coefficient is zero.

\section{REFERENCES}

Angevine, W. M., 2005: An integrated turbulence scheme for boundary layers with shallow cumulus applied to pollutant transport. J. Appl. Meteor., 44, 1436-1452, https://doi.org/ 10.1175/JAM2284.1.
— H. Jiang, and T. Mauritsen, 2010: Performance of an eddy diffusivity-mass flux scheme for shallow cumulus boundary layers. Mon. Wea. Rev., 138, 2895-2912, https://doi.org/ 10.1175/2010MWR3142.1.

- , L. Eddington, K. Durkee, C. Fairall, L. Bianco, and J. Brioude, 2012: Meteorological model evaulation for CalNex 2010. Mon. Wea. Rev., 140, 3885-3906, https://doi.org/10.1175/ MWR-D-12-00042.1.

— regions. J. Geophys. Res. Atmos., 118, 6750-6763, https:// doi.org/10.1002/jgrd.50490.

_ J. Brioude, S. McKeen, and J. S. Holloway, 2014: Uncertainty in Lagrangian pollutant transport simulations due to meteorological uncertainty from a mesoscale WRF ensemble. Geosci. Model Dev., 7, 2817-2829, https://doi.org/10.5194/ gmd-7-2817-2014.

Arakawa, A., 2004: The cumulus parameterization problem: Past, present, and future. J. Climate, 17, 2493-2525, https:// doi.org/10.1175/1520-0442(2004)017<2493:RATCPP $>2.0$. $\mathrm{CO} ; 2$.

Baas, P., F. C. Bosveld, G. Lenderink, E. van Meijgaard, and A. A. M. Holtslag, 2010: How to design single-column model experiments for comparison with observed nocturnal lowlevel jets. Quart. J. Roy. Meteor. Soc., 136, 671-684, https:// doi.org/10.1002/qj.592.

Basu, S., A. A. M. Holtslag, B. J. H. Van de Weil, A. F. Moene, and G.-J. Steeneveld, 2008: An inconvenient "truth" about using sensible heat flux as a surface boundary condition in models under stably stratified regimes. Acta Geophys., 56, 88-99, https://doi.org/10.2478/s11600-007-0038-y.

Beare, R. J., and Coauthors, 2006: An intercomparison of large-eddy simulations of the stable boundary layer. Bound.-Layer Meteor., 118, 247-272, https://doi.org/10.1007/s10546-004-2820-6.

Benjamin, S. G., and Coauthors, 2016: A North American hourly assimilation and model forecast cycle: The Rapid Refresh. Mon. Wea. Rev., 144, 1669-1694, https://doi.org/10.1175/ MWR-D-15-0242.1.

Bosveld, F., and Coauthors, 2014: The third GABLS intercomparison case for evaluation studies of boundary-layer models. Part B: Results and process understanding. Bound.-Layer Meteor., 152, 157-187, https://doi.org/10.1007/s10546-014-9919-1.

Cadeddu, M. P., J. C. Liljegren, and D. D. Turner, 2013: The Atmospheric Radiation Measurement (ARM) program network of microwave radiometers: Instrumentation, data, and 
retrievals. Atmos. Meas. Tech., 6, 2359-2372, https://doi.org/ 10.5194/amt-6-2359-2013.

Cahalan, R. F., and J. H. Joseph, 1989: Fractal statistics of cloud fields. Mon. Wea. Rev., 117, 261-272, https://doi.org/10.1175/ 1520-0493(1989)117<0261:FSOCF >2.0.CO;2.

Cancelli, D. M., M. Chamecki, and N. L. Dias, 2014: A large-eddy simulation study of scalar dissimilarity in the convective atmospheric boundary layer. J. Atmos. Sci., 71, 3-15, https://doi.org/10.1175/JAS-D-13-0113.1.

Chaboureau, J.-P., and P. Bechtold, 2002: A simple cloud parameterization derived from cloud resolving model data: Diagnostic and prognostic applications. J. Atmos. Sci., 59, 2362-2372, https:// doi.org/10.1175/1520-0469(2002)059<2362:ASCPDF>2.0.CO;2.

$\longrightarrow$, and - 2005: Statistical representation of clouds in a regional model and the impact on the diurnal cycle of convection during Tropical Convection, Cirrus and Nitrogen Oxides (TROCCINOX). J. Geophys. Res., 110, D17103, https:// doi.org/10.1029/2004JD005645.

Chatfield, R. B., and R. A. Brost, 1987: A two-stream model of the vertical transport of trace species in the convective boundary layer. J. Geophys. Res., 92, 13 263-13 276, https://doi.org/10.1029/ JD092iD11p13263.

Clothiaux, E. E., T. P. Ackerman, G. G. Mace, K. P. Moran, R. T. Marchand, M. A. Miller, and B. E. Martner, 2000: Objective determination of cloud heights and radar reflectivities using a combination of active remote sensors at the ARM CART sites. J. Appl. Meteor., 39, 645-665, https://doi.org/10.1175/ 1520-0450(2000)039<0645:ODOCHA > 2.0.CO;2.

De Roode, S. R., A. P. Siebesma, H. J. J. Jonker, and Y. de Voogd, 2012: Parameterization of the vertical velocity equation for shallow cumulus clouds. Mon. Wea. Rev., 140, 2424-2436, https://doi.org/10.1175/MWR-D-11-00277.1.

Gustafson, W. I., A. M. Vogelmann, X. Cheng, S. Endo, B. Krishna, Z. Li, T. Toto, and H. Xiao, 2017a: Recommendations for the implementation of the LASSO workflow. DOE Tech. Rep. DOE/ SC-ARM-17-031, DOE Atmospheric Radiation Measurement Climate Research Facility, 62 pp., https://doi.org/10.2172/1406259.

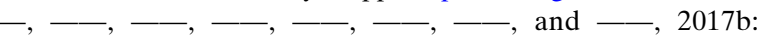

LASSO Alpha 1 data bundles: $36^{\circ} 36^{\prime} 18.0^{\prime \prime} \mathrm{N}, 97^{\circ} 29^{\prime} 6.0^{\prime \prime} \mathrm{W}$ : Southern Great Plains Central Facility (C1). ARM Data Archive, Oak Ridge, TN, accessed 18 July 2016, https://doi.org/ 10.5439/1256454.

scription of the LASSO Alpha $1-\overline{1},-,-$, and $-, 2017 \mathrm{c}:$ DeRadiation Measurement Research Facility, DOE/SC-ARMTR-194, https://doi.org/10.2172/1373564.

Hacker, J. P., and W. M. Angevine, 2013: Ensemble data assimilation to characterize surface-layer errors in numerical weather prediction models. Mon. Wea. Rev., 141, 1804-1821, https://doi.org/10.1175/MWR-D-12-00280.1.

Han, J., M. L. Witek, J. Teixeira, R. Sun, H.-L. Pan, J. K. Fletcher, and C. S. Bretherton, 2016: Implementation in the NCEP GFS of a Hybrid Eddy-Diffusivity Mass-Flux (EDMF) boundary layer parameterization with dissipative heating and modified stable boundary layer mixing. Wea. Forecasting, 31, 341-352, https://doi.org/10.1175/WAF-D-15-0053.1.

Heinze, R., C. Moseley, L. N. Böske, S. K. Muppa, V. Maurer, S. Raasch, and B. Stevens, 2017: Evaluation of large-eddy simulations forced with mesoscale model output for a multiweek period during a measurement campaign. Atmos. Chem. Phys., 17, 7083-7109, https://doi.org/10.5194/acp-17-7083-2017.

Hourdin, F., F. Couvreux, and L. Menut, 2002: Parameterization of the dry convective boundary layer based on a mass flux representation of thermals. J. Atmos. Sci., 59, 1105-1123, https:// doi.org/10.1175/1520-0469(2002)059<1105:POTDCB >2.0.CO;2.

$\mathrm{Hu}$, M., S. G. Benjamin, T. T. Ladwig, D. C. Dowell, S. S. Weygandt, D. C. Alexander, and J. S. Whitaker, 2017: GSI three-dimensional ensemble-variational hybrid data assimilation using a global ensemble for the regional Rapid Refresh model. Mon. Wea. Rev., 145, 4205-4225, https://doi.org/ 10.1175/MWR-D-16-0418.1.

Huang, H.-Y., A. Hall, and J. Teixeira, 2013: Evaluation of the WRF PBL parameterizations for marine boundary layer clouds: Cumulus and stratocumulus. Mon. Wea. Rev., 141, 2265-2271, https://doi.org/10.1175/MWR-D-12-00292.1.

Knuteson, R. O., and Coauthors, 2004: Atmospheric Emitted Radiance Interferometer. Part I: Instrument design. J. Atmos. Oceanic Technol., 21, 1763-1776, https://doi.org/10.1175/ JTECH-1662.1.

Köhler, M., M. Ahlgrimm, and A. Beljaars, 2011: Unified treatment of dry convective and stratocumulus-topped boundary layers in the ECMWF model. Quart. J. Roy. Meteor. Soc., 137, 43-57, https://doi.org/10.1002/qj.713.

Larsen, X. G., M. Kelly, and A. M. Sempreviva, 2014: On the temperature and humidity dissimilarity in the marine surface layer. Bound.-Layer Meteor., 151, 273-291, https://doi.org/10.1007/ s10546-013-9896-9.

Li, Z., J. C. McWilliams, K. Ide, and J. Farrara, 2015a: A multiscale variational data assimilation scheme: Formulation and illustration. Mon. Wea. Rev., 143, 3804-3822, https://doi.org/10.1175/ MWR-D-14-00384.1.

—, S. Feng, Y. Liu, W. Lin, M. Zhang, T. Toto, A. M. Vogelmann, and S. Endo, 2015b: Development of fineresolution analyses and expanded large-scale forcing properties: 1. Methodology and evaluation. J. Geophys. Res. Atmos., 120, 654-666, https://doi.org/10.1002/2014JD022245.

Ma, H. Y., and Coauthors, 2018: CAUSES: On the role of surface energy budget errors to the warm surface air temperature error over the central United States. J. Geophys. Res. Atmos., 123, 2888-2909, https://doi.org/10.1002/2017JD027194.

Mielikainen, J., B. Huang, and H. L. A. Huang, 2015: Optimizing Total Energy-Mass Flux (TEMF) planetary boundary layer scheme for Intel's Many Integrated Core (MIC) architecture. IEEE J. Sel. Top. Appl. Earth Obs. Remote Sens., 8, 41064119, https://doi.org/10.1109/JSTARS.2015.2438638.

Nakanishi, M., and H. Niino, 2009: Development of an improved turbulence closure model for the atmospheric boundary layer. J. Meteor. Soc. Japan Ser. II, 87, 895-912, https://doi.org/ 10.2151/jmsj.87.895.

Neggers, R. A. J., 2015: Exploring bin-macrophysics models for moist convective transport and clouds. J. Adv. Model. Earth Syst., 7, 2079-2104, https://doi.org/10.1002/2015MS000502.

, H. J. J. Jonker, and A. P. Siebesma, 2003: Size statistics of cumulus cloud populations in large-eddy simulations. J. Atmos. Sci., 60, 1060-1074, https://doi.org/10.1175/1520-0469(2003)60<1060: $\mathrm{SSOCCP}>2.0 . \mathrm{CO} ; 2$.

— A. P. Siebesma, G. Lenderink, and A. A. Holtslag, 2004: An evaluation of mass flux closures for diurnal cycles of shallow cumulus. Mon. Wea. Rev., 132, 2525-2538, https://doi.org/ 10.1175/MWR2776.1.

, M. Koehler, and A. C. M. Beljaars, 2009: A dual mass flux framework for boundary layer convection. Part I: Transport. J. Atmos. Sci., 66, 1465-1487, https://doi.org/10.1175/ 2008JAS2635.1.

, A. P. Siebesma, and T. Heus, 2012: Continuous single-column model evaluation at a permanent meteorological supersite. Bull. 
Amer. Meteor. Soc., 93, 1389-1400, https://doi.org/10.1175/ BAMS-D-11-00162.1.

Pergaud, J., V. Masson, S. Malardel, and F. Couvreux, 2009: A parameterization of dry thermals and shallow cumuli for mesoscale numerical weather prediction. Bound.-Layer Meteor., 132, 83-106, https://doi.org/10.1007/s10546-009-9388-0.

Rio, C., and F. Hourdin, 2008: A thermal plume model for the convective boundary layer: Representation of cumulus clouds. J. Atmos. Sci., 65, 407-425, https://doi.org/10.1175/ 2007JAS2256.1.

Siebesma, A. P., and J. Teixeira, 2000: An advection-diffusion scheme for the convective boundary layer: Description and 1D results. 14th Symp. on Boundary Layer and Turbulence, Aspen, CO, Amer. Meteor. Soc., 4.16, https://ams.confex.com/ ams/AugAspen/techprogram/paper_14840.htm.

— P. M. M. Soares, and J. Teixeira, 2007: A combined eddydiffusivity mass-flux approach for the convective boundary layer. J. Atmos. Sci., 64, 1230-1248, https://doi.org/10.1175/JAS3888.1.

Simpson, J., and V. Wiggert, 1969: Models of precipitating cumulus towers. Mon. Wea. Rev., 97, 471-489, https://doi.org/10.1175/ 1520-0493(1969)097<0471:MOPCT > 2.3.CO;2.

Sisterson, D. L., R. A. Peppler, T. S. Cress, P. J. Lamb, and D. D. Turner, 2016: The ARM Southern Great Plains (SGP) Site. The Atmospheric Radiation Meaurement (ARM) Program: The First 20 Years, Meteor. Monogr., No. 57, 6.1-6.14, https:// doi.org/10.1175/AMSMONOGRAPHS-D-16-0004.1.

Sušelj, K., J. Teixeira, and G. Matheou, 2012: Eddy diffusivity/mass flux and shallow cumulus boundary layer: An updraft PDF multiple mass flux scheme. J. Atmos. Sci., 69, 1513-1533, https://doi.org/10.1175/JAS-D-11-090.1.

,-- , and D. Chung, 2013: A unified model for moist convective boundary layers based on a stochastic eddy-diffusivity/ mass-flux parameterization. J. Atmos. Sci., 70, 1929-1953, https://doi.org/10.1175/JAS-D-12-0106.1.

T. F. Hogan, and J. Teixeira, 2014: Implementation of a stochastic eddy-diffusivity/mass-flux parameterization into the
Navy Global Environmental Model. Wea. Forecasting, 29, 1374-1390, https://doi.org/10.1175/WAF-D-14-00043.1.

Svensson, G., and Coauthors, 2011: Evaluation of the diurnal cycle in the atmospheric boundary layer over land as represented by a variety of single column models-The second GABLS experiment. Bound.-Layer Meteor., 140, 177-206, https:// doi.org/10.1007/s10546-011-9611-7.

Tang, S., M. Zhang, and S. Xie, 2017: Investigating the dependence of SCM simulated precipitation and clouds on the spatial scale of large-scale forcing at SGP. J. Geophys. Res. Atmos., 122, 8724-8738, https://doi.org/10.1002/2017JD026565.

Tian, Y., and Z. Kuang, 2016: Dependence of entrainment in shallow cumulus convection on vertical velocity and distance to cloud edge. Geophys. Res. Lett., 43, 4056-4065, https://doi.org/10.1002/ 2016GL069005.

Turner, D. D., 2007: Improved ground-based liquid water path retrievals using a combined infrared and microwave approach. J. Geophys. Res., 112, D15204, https://doi.org/10.1029/2007JD008530.

—, and U. Loehnert, 2014: Information content and uncertainties in thermodynamic profiles and liquid cloud properties retrieved from the ground-based Atmospheric Emitted Radiance Interferometer (AERI). J. Appl. Meteor. Climatol., 53, 752-771, https://doi.org/10.1175/JAMC-D-13-0126.1.

— thermodynamic profile retrieval algorithm. IEEE J. Sel. Top. Appl. Earth Obs. Remote Sens., https://doi.org/10.1109/ JSTARS.2018.2874968, in press.

Van Weverberg, K., and Coauthors, 2018: CAUSES: Attribution of surface radiation biases in NWP and climate models near the U.S. Southern Great Plains. J. Geophys. Res. Atmos., 123, 3612-3644, https://doi.org/10.1002/2017JD027188.

Yang, B., and Coauthors, 2017: Sensitivity of turbine-height wind speeds to parameters in planetary boundary-layer and surfacelayer schemes in the Weather Research and Forecasting Model. Bound.-Layer Meteor., 162, 117-142, https://doi.org/ 10.1007/s10546-016-0185-2. 